\title{
A new method for retrieval of the extinction coefficient of water clouds by using the tail of the CALIOP signal
}

\author{
J. Li ${ }^{1,2}$, Y. Hu ${ }^{3}$, J. Huang ${ }^{1}$, K. Stamnes ${ }^{2}$, Y. Yi ${ }^{4}$, and S. Stamnes ${ }^{2}$ \\ ${ }^{1}$ Key Laboratory for Semi-Arid Climate Change of the Ministry of Education College of Atmospheric Sciences, \\ Lanzhou University, Lanzhou, China \\ ${ }^{2}$ Dept. of Physics and Engineering, Stevens Institute of Tech., Hoboken, NJ, USA \\ ${ }^{3}$ Climate Science Branch, NASA Langley Research Center, Hampton, Virginia, USA \\ ${ }^{4}$ Science Systems and Applications Inc., Hampton, Virginia, USA \\ Received: 9 September 2010 - Published in Atmos. Chem. Phys. Discuss.: 17 November 2010 \\ Revised: 22 February 2011 - Accepted: 24 March 2011 - Published: 29 March 2011
}

\begin{abstract}
A method is developed based on CloudAerosol Lidar and Infrared Pathfinder Satellite Observations (CALIPSO) level 1 attenuated backscatter profile data for deriving the mean extinction coefficient of water droplets close to cloud top. The method is applicable to low level (cloud top $<2 \mathrm{~km}$ ), opaque water clouds in which the lidar signal is completely attenuated beyond about $100 \mathrm{~m}$ of penetration into the cloud. The photo multiplier tubes (PMTs) of the $532 \mathrm{~nm}$ detectors (parallel and perpendicular polarizations) of the Cloud-Aerosol Lidar with Orthogonal Polarization (CALIOP) both exhibit a non-ideal recovery of the lidar signal after striking a strongly backscattering target (such as water cloud or surface). Therefore, the effects of any transient responses of CALIOP on the attenuated backscatter profile of the water cloud must first be removed in order to obtain a reliable (validated) attenuated backscatter profile. Then, the slope of the exponential decay of the validated water cloud attenuated backscatter profile, and the multiple scattering factor are used for deriving the mean extinction coefficient of low-level water cloud droplets close to cloud top. This novel method was evaluated and compared with the previous method which combined the cloud effective radius $(3.7-\mu \mathrm{m})$ reported by MODIS with the lidar depolarization ratios measured by CALIPSO to estimate the mean extinction coefficient. Statistical results show that the extinction coefficients derived by the new method based on CALIOP alone agree reasonbably well with those obtained in the previous study using combined CALIOP and MODIS data. The mean absolute relative difference in extinction coefficient is about $13.4 \%$. An important advantage of the new method is that it can be used to derive the
\end{abstract}

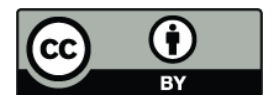

Correspondence to: $\mathrm{Y} . \mathrm{Hu}$

(yongxiang.hu-1@ nasa.gov) extinction coefficient also during night time, and it is also applicable when multi-layered clouds are present. Overall, the stratocumulus dominated regions experience larger day-night differences which are all negative and seasonal. However, a contrary tendency consisted in the global mean values. The global mean cloud water extinction coefficients during different seasons range from 26 to $30 \mathrm{~km}^{-1}$, and the differences between day and night time are all positive and small (about $1-2 \mathrm{~km}^{-1}$ ). In addition, the global mean layer-integrated depolarization ratios of liquid water clouds during different seasons range from 0.2 to 0.23 , and the differences between day and night also are small, about 0.01 .

\section{Introduction}

Low level water clouds (such as stratiform clouds within the boundary layer) are observed to occur very persistently, and to cover large areas of the globe, in particular, over the tropics and subtropics (Hartmann and Short, 1980). Since low level water clouds generally have high albedos relative to the ocean surface, these clouds significantly decrease the amount of solar energy absorbed by the earth system, thus reduce heating rates as compared to cloud free conditions and have a significant cooling effect on global climate (e.g. Randall et al., 1984; Fouquart et al., 1990; Betts and Boers, 1990). Their net radiative effect on the global energy budget has been estimated at $-15 \mathrm{Wm}^{-2}$ and the sensitivity to changes in global low cloud coverage at $-0.63 \mathrm{Wm}^{-2}$ (Hartmann et al., 1992) for each percent increase in low cloud amount. The impact of these water clouds on the radiation budget and the amount of energy that they absorb depend both upon their microphysical (such as, effective droplet radius) and macrophysical properties (such as, height, coverage) (e.g. Charlson

Published by Copernicus Publications on behalf of the European Geosciences Union. 
et al., 1987; Albrecht et al., 1988; Kiehl, 1994). For example, Slingo (1990) estimated that reducing the effective diameter of stratus cloud droplet sizes from 20 to $16 \mu \mathrm{m}$ would balance the warming due to a doubling of atmospheric $\mathrm{CO}_{2}$. Randall et al. (1984) estimated that a $4 \%$ increase in the area of the globe covered by these clouds could also potentially compensate for the estimated warming due to a doubling of atmospheric $\mathrm{CO}_{2}$. Therefore, it is very important to know the global distribution of water cloud microphysical, macrophysical and radiative properties and their relationship in order to assess the impact of these clouds on the climate system.

Ground based (e.g. Fox and Illingworth, 1997; Wang et al., 2004; O'Connor et al., 2005; Illingworth et al., 2007) and satellite observations (e.g. Masunaga et al., 2002a, b; Schüller et al., 2003, 2005; Wood et al., 2005a, b, 2006) can help diagnose cloud microphysical and macrophysical properties and their link to cloud radiative and precipitation properties. However, although the cloud properties can be retrieved relatively accurately from ground based lidar or radar signals (e.g. Derr, 1980; Wang and Sassen, 2001; Westbrook et al., 2010), only one-dimensional observations are possible, and the sites are sparsely distributed, almost non-existent over the oceans. So, results from ground observational measurements are commonly used to validate and evaluate satellite remote sensing retrievals (e.g. Tao et al., 2008; Mamouri et al., 2009; Kim et al., 2008; Mona et al., 2007). The advantage of remote sensing observations from instruments deployed on satellites is that high-resolution, two-dimensional distributions of the micro and macrophysical properties of clouds may be retrieved on a global scale. In this investigation, we will develop a novel method to assess the extinction coefficient of low-level water clouds on a global scale by using space-based lidar (CALIPSO) attenuated backscatter data.

Previous studies (e.g. Boers and Mitchell, 1994; Duynkerke et al., 1995; Pawlowska and Brenguier, 2000) show that profiles of liquid water content in actual stratiform boundary layer clouds follow the so-called adiabatic cloud model. That is, for many water clouds the liquid water content increases linearly with height. But, the droplet number concentration within the cloud has an approximately constant value. As a result, the extinction coefficient and droplet radius in water clouds both increase with height above cloud base. However, since boundary layer clouds frequently exceed CALIOP's detection limit of effective optical depth $(\eta \tau<3, \eta$ is multiple scattering factor and $\tau$ is optical depth ) (Hu et al., 2007b; Chand et al., 2008), the lidar signal can be completely attenuated within a penetration depth of about $100 \mathrm{~m}$ for most boundary layer clouds with modest and low extinctions. So, in this paper, only mean microphysical properties in the top part of water cloud can be derived from the new method. However, the vertical change of the extinction coefficient within the top $100 \mathrm{~m}$ is relatively small compared with the mean extinction coefficient value. Although, the veritcal profile of the extinction coefficient within the entire water cloud layer cannot be derived by the method developed here, this study about the microphysical properties of the top part of the water cloud is still meaningful and valid. It can help retrieve the droplet number concentration, which has less vertical variation.

Hu et al. (2007a) already derived the mean extinction coefficient, liquid water content and droplet number concentration of low-level water cloud tops by using collocated water cloud droplet sizes retrieved from MODIS data and CALIPSO level 2 cloud products. Nonetheless, the water cloud measurements made by active remote sensing instruments (such as, space-based lidar) are very different from those made by passive remote sensing instruments (such as MODIS). Passive remote sensing of water clouds, based on measured spectral differences of reflected sunlight and thermal emissions, is used to retrieve values of optical depth for the entire vertical column. The passive sensors provide the effective droplet radius using the absorption at near infrared wavelengths in the solar spectrum, and are based on the single-layer cloud assumption. So, retrievals of water cloud extinction properties based on MODIS effective radius measurements are limited to the daytime and are valid only when the single-layer cloud condition is satisfied. However, a space-based lidar (such as CALIPSO) obtains information about the cloud from the backscattered lidar signal. Thus, a lidar can provide the atmospheric attenuated backscatter profile, and is not confined to daytime conditions and a singlelayer cloud structure.

The objective of this study is to provide better knowledge of water cloud physical properties and their impact on the surface energy budget from a comparison of optical properties of water clouds between day and night. The global statistics of nighttime water cloud optical properties derived in this study is a valuable supplement to daytime retrieval results based on passive remote sensing of scattered sunlight, and can provide additional information about cloud properties such day-night variations.

This study is organized as follows. The retrieval method is introduced in Sect. 2. In Sect. 3 we compare results between the new method and previous studies. Finally, a brief discussion and conclusions are provided in Sect. 4.

\section{Methodology}

Monte Carlo simulations indicate that by using layer integrated depolarization ratios and the slope of the exponential decay in the water cloud backscatter due to multiple scattering, both extinction coefficients and effective radii of water clouds can be derived from CALIPSO lidar measurements (Hu et al., 2007a). In view of the multiple scattering effect, the attenuated backscatter can be expressed as (Platt, 1979, 1981):

$\beta=\beta_{0} e^{-2 \eta \sigma r}$ 
where $\sigma$ is the mean extinction coefficient near cloud top, $r$ is the range within the water cloud top, and $\eta$ is the corresponding multiple scattering factor. $\beta_{0}$ is the peak value of the attenuated backscatter within water cloud. By taking the natural logarithm on both sides of Eq. (1), we have

$\eta \sigma=\frac{\ln \beta-\ln \beta_{0}}{-2 r}$

where $\beta$ and $\beta_{0}$ can be obtained from CALIPSO level 1 and level 2 datasets. The CALIPSO lidar probes cloud and aerosol layers to a maximum effective optical depth $(\eta \tau)$ of 3 (Hu et al., 2007b; Chand et al., 2008), and the layers with larger optical depths are opaque. However, boundary layer clouds frequently exceed this optical depth, therefore in this study we focus on cloud properties near the top of opaque, low level water clouds. As a result, for these opaque and dense water clouds, the limitation of an effective optical depth $(\eta \tau<3)$ below cloud top corresponds to a penetration depth of about $100 \mathrm{~m}$ within the cloud, that is, near the cloud top.

The importance of multiple scattering of polarized light in the atmosphere has been recognized for a long time (e.g. Hansen, 1970a, 1970b). For space lidars such as CALIPSO (Winker et al., 2003), which has a footprint size of $90 \mathrm{~m}$ at the Earths surface, water clouds can exhibit a strong depolarization signal due to the presence of multiple scattering (Hu et al., 2001). Thus, multiple scattering plays an important role in the analysis of the lidar signal. $\mathrm{Hu}$ et al. (2006) proposed a relationship between the integrated single scattering fraction and the accumulated linear depolarization ratio for water droplets. A simplified version of this relation is: $\eta=\left(\frac{1-\delta}{1+\delta}\right)^{2}$ (Hu et al., 2007c), where, $\delta=$ $\int_{\text {top }}^{\text {base }} \beta_{\perp}(r) d r / \int_{\text {top }}^{\text {base }} \beta_{\|}(r) d r$ is the layer-integrated depolarization ratio. This relationship is very valid when the layerintegrated depolarization ratio is smaller than 0.35. Cao et al. (2009) extended the idea of the accumulated depolarization for circular polarization and proposed a unique relation between the integrated single scattering fraction and the depolarization parameter, which does not depend on whether linear or circular lidar polarization is being used. This relation is independent of the measurement geometry, and the mean droplet size, and is insensitive to the width of the size distribution for most water cloud lidar returns ( $\mathrm{Hu}$ et al., 2007a). By their studies, the multiple scattering effect of water cloud was characterized very well.

Generally speaking, if we adopt the multiple scattering relationship: $\eta=\left(\frac{1-\delta}{1+\delta}\right)^{2}$ in Eq. (2), we can easily derive the extinction coefficient $\sigma$ from the slope of the exponential decay of the water-cloud attenuated backscatter $\beta$ and multiple scattering factor $\eta$ (hereafter, we call it the "slope method"). However, the $532 \mathrm{~nm}$ photo multiplier tube (PMT) detectors (parallel and perpendicular) of CALIOP both exhibit a non-ideal recovery of the lidar signal after a strong backscattering target has been observed. In the absence of a strong backscattering signal, an ideal detector will return
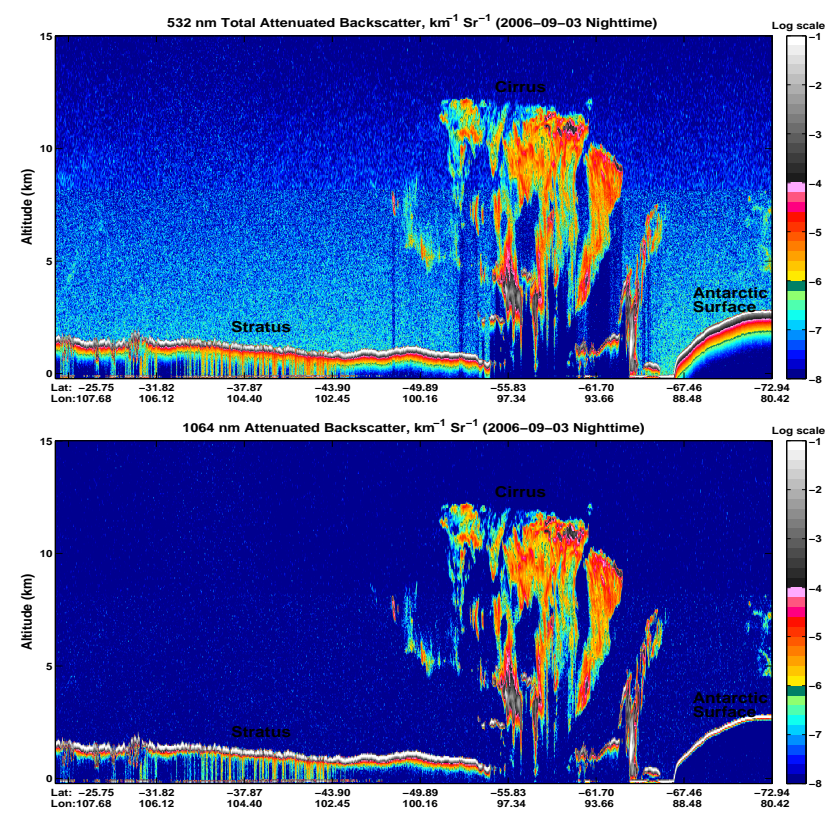

Fig. 1. CALIPSO data images of $532 \mathrm{~nm}$ (top panel) and $1064 \mathrm{~nm}$ (bottom panel) total attenuated backscatter.

immediately to its baseline state. However, the transient response of the CALIPSO PMTs is non-ideal. Following a strong impulse signal, such as from the Earths surface or a dense water cloud, the signal initially falls off as expected but at some point begins decaying at a slower rate that is approximately exponential with respect to time (distance). In extreme cases, the non-ideal transient recovery can make it wrongly appear as if the laser signal is penetrating the surface to a depth of several hundreds of meters (e.g. McGill et al., 2007; Hunt et al., 2009). So, because of the nonideal transient recovery, the return from strong targets will be spread by the instrument response function over several adjacent range bins, implying that the vertical distribution of the attenuated backscatter $\beta$ in the water cloud will be changed. It is unlikely that the lidar receiver electronics are the source of the problem because the $1064 \mathrm{~nm}$ channel uses a similar design and is performing well. To demonstrate this phenomenon, Fig. 1 shows CALIPSO data images of $532 \mathrm{~nm}$ (top panel) and $1064 \mathrm{~nm}$ (bottom panel) total attenuated backscatter. The $532 \mathrm{~nm}$ non-ideal transient recovery is seen in the $532 \mathrm{~nm}$ image as a gradual transition of colors from high attenuated backscatter values to lower ones for strong backscatter targets (e.g. stratus deck on the left, and the Antarctic surface return on the right). Compare these features to the $1064 \mathrm{~nm}$ image, where the detector response is normal, and these features appear as an almost solid band of white. For example, the right parts of the $532 \mathrm{~nm}$ and $1064 \mathrm{~nm}$ images (that is, the Antarctic surface) clearly illustrate that the $532 \mathrm{~nm}$ signal appears to continue hundreds of $\mathrm{m}$ beneath the ice surface while the $1064 \mathrm{~nm}$ signal does 
not exhibit this behavior. However, it is worth noticing that the cirrus cloud structure (center right) looks about the same in both the $532 \mathrm{~nm}$ and $1064 \mathrm{~nm}$ images, because there is little to no contribution from the transient response artifact in these weak scattering features. This non-ideal transient recovery is well documented in the literature on photon counting applications, and is likely due to the after-pulsing of the PMT (ionization of residual gas). The time scale of the effect depends on gas species, and PMT voltage and internal geometry.

So, in view of the non-ideal transient recovery of the CALIOP PMTs, profiles of attenuated backscatter $\beta$ in the water cloud were contaminated and can not directly be used to calculate the extinction coefficient of water cloud by the slope method. To retrieve a valid extinction coefficient $\sigma$, we will take the following three steps:

1. In view of the above discussions, the transient response function of CALIOP is a very important parameter and the basis of this study. Since a hard land surface cannot easily be penetrated by the CALIOP signal, the return from a land surface should be distributed in single vertical bin under ideal conditions. Therefore, a hard land surface should be a good target for studies of the transient response function. The strong return within one single vertical lidar bin from a hard land surface can be used to quantify how the return from a dense cloud was spread by the instrument response function over several adjacent range bins. So, in the first step, we obtain the response function by studying CALIOP lidar signals returned from land surfaces.

2. Second, we apply a simple de-convolution process to the attenuated backscatter lidar signal and the transient response function of CALIOP in order to remove any impacts on the attenuated backscatter profile of water cloud imparted by a non-ideal transient response of the PMTs and get the corrected attenuated backscatter lidar signal of the water cloud.

3. Finally, after obtaining a valid and corrected attenuated backscatter profile of the water cloud by the former two steps, we can retrieve the extinction coefficient $\sigma$ of water cloud from Eq. (2).

\subsection{Transient response function of CALIOP}

Prior to launch, extensive laboratory characterization of the flight detectors and their associated electronics demonstrated that the CALIPSO PMTs transient response remains the same for lidar surface returns with varing surface reflectance. This result can be independently verified using on-orbit data by studying CALIPSO's lidar signal from surfaces. It is worth noticing that the strongest of the CALIPSO backscatter signals are generated by ocean and land surfaces that are covered by snow or ice (see the Antarctic surface return part of
Fig. 1). In the $532 \mathrm{~nm}$ parallel channel, the peak signals from snow and ice surfaces under clear skies are so strong that they usually saturate the detectors. Unlike the parallel component, the cross-polarized (perpendicular) component of the ground returns for most land and ocean surfaces are generally not saturated. As a result, in this study, only land surfaces that are not covered by snow or ice were used to assess the transient response of CALIOP at three channels. We analyze the CALIOP transient response for different land surface types using on-orbit CALIPSO Level-1 data (July 2006, October 2006, January 2007) at different regions by using a low-pass filter. As shown in a previous study (Hu et al., 2007d) more than $90 \%$ the surface return energy comes from the three 30 meter vertical range bins including the bin that contains the surface echo. These bins correspond to that of the peak return itself as well as one bin before and one after the peak return. Thus, we may calculate the transient response function $F$ of CALIOP as follows:

$$
F_{j}=\frac{\beta_{i}}{\sum_{i=p-1}^{i=p+10} \beta_{i}} \quad(j=1,2,3,4, \ldots, 12)
$$

by using twelve adjacent lidar bins of land surface returns. The twelve range bins starting from the one range bin before the peak to the tenth range bin after the surface peak return. Here $\beta_{i}$ is the attenuated backscatter of each bin, which is the same $\beta$ as in Eqs. (1) and (2), $i$ is the range bin number, and $p$ is the peak surface return range bin. Hu et al. (2007d) already presented a technique to provide improved lidar altimetry from CALIPSO lidar data by using the transient response of CALIOP, and verified that the tail-to-peak signal ratios are independent of the surface reflectance.

Figure 2 shows the transient response function $F$ of CALIOP derived from the land surface return at three channels. The different colors are for different regions (surface types are different) and seasons. The left, middle and right panels are for the parallel channel (P532), perpendicular channel (S532) and T532 channel (perpendicular and parallel components), respectively. It is clear that the transient response of CALIOP for different months and surface types are almost same. Although the method described in this study can be applied to both $532 \mathrm{~nm}$ channels (parallel and perpendicular polarization), only the results from the $532 \mathrm{~nm}$ parallel channel are presented in this paper.

\subsection{Corrected water cloud attenuated backscatter}

Actually, the current water cloud attenuated backscatter signal measured by CALIOP results from a convolution between the corrected cloud attenuated backscatter and the transient response function $F$ of CALIOP. This convolution process can be described mathematically as follows

$$
\begin{aligned}
& \beta_{\text {corrected }}^{1} \times F_{1}=\beta_{\text {current }}^{0} \\
& \beta_{\text {corrected }}^{1} \times F_{2}+\beta_{\text {corrected }}^{2} \times F_{1}=\beta_{\text {current }}^{1}
\end{aligned}
$$



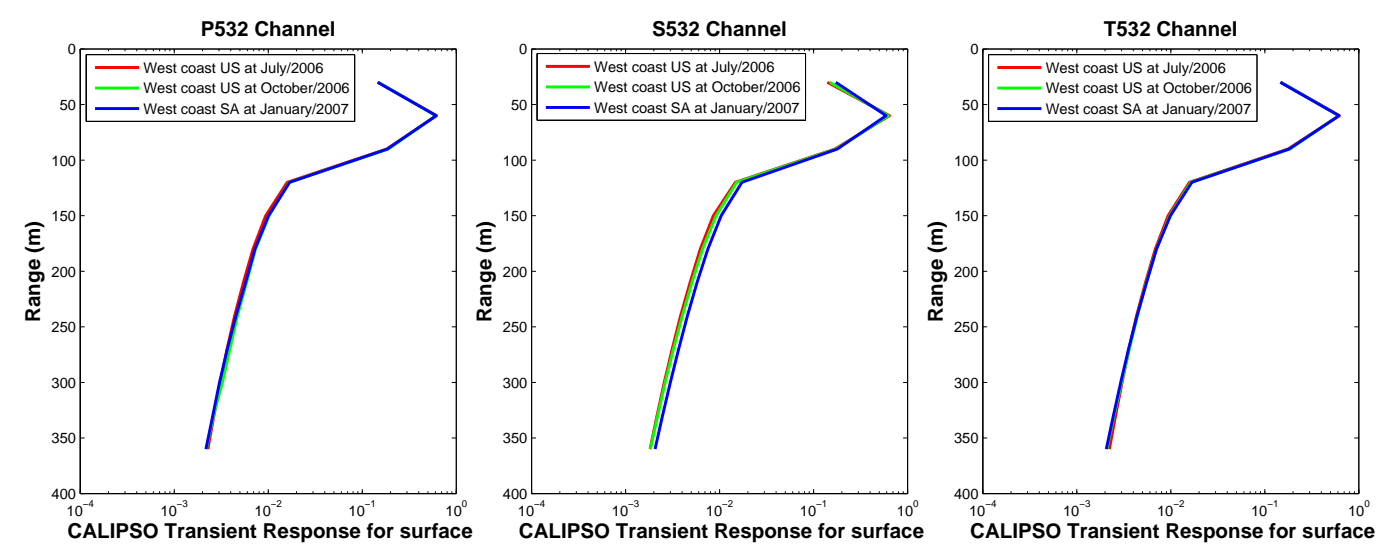

Fig. 2. Transient response of CALIOP derived from the land surface return at different months and different regions for three channels.

$\vdots=\vdots$

$\sum_{i=1}^{n} \beta_{\text {corrected }}^{i} \times F_{n-i+1}=\beta_{\text {current }}^{i-1} \quad(n=1,2,3,4, \ldots)$

After obtaining the transient response function $F$ of CALIOP, we can use it in conjunction with the current lidar signal to retrieve the corrected water cloud attenuated backscatter signal by reversing the convolution process described by Eqs. (4)-(7), which corresponds to a deconvolution process. Before the de-convolution process, we must do some horizontal averaging of the vertical lidar profiles (using for example, 30 profiles) in order to eliminate possible negative values in the water cloud profiles due to filter noise. Then, we may start the de-convolution process from several bins (here, we only use one bin) which have very weak air backscatter value above the water clouds. For example, in Eq. (4), $\beta_{\text {current }}^{0}$ consists of weak backscatter from the air just above the cloud, as well as backscatter from the first bin within the water cloud. Compared to the backscatter from the first cloud bin, the backscatter from the air just above the cloud is very weak and can be neglected. Thus, $\beta_{\text {current }}^{0}$ is the backscatter signal from the first bin within the water cloud, and $\beta_{\text {corrected }}^{1}$ is the corrected backscatter value of first bin of the water cloud profile, and $\beta_{\text {current }}^{1}$ is the current backscatter value of first bin of the water cloud profile. By continuing this de-convolution process, eventually, the corrected backscatter signals of all bins can be derived.

Figure 3 shows the cloud attenuated backscatter signal retrieved beneath the water cloud peak return and the observed attenuated backscatter signal by CALIOP. The red line is observed (current) water cloud attenuated backscatter signal and the blue line is the retrieval (corrected or real) cloud signal. The results show that the transient response of CALIOP PMTs can affect the vertical distribution (that is, the waveform) and magnitude of the water cloud attenuated backscatter signal. After the de-convolution process, the slope of the exponential decay of the water cloud attenuated backscatter, may be obtained by using a simple linear fit to the several range bins underneath the peak of the water cloud lidar return and the peak return bin itself. According to Eq. (2), the extinction coefficient of the low-level water cloud top thus can be derived from the slope and multiple scattering factor of the water cloud.

\section{Results}

\subsection{Comparison of extinction coefficients derived from different methods}

Hu et al. (2007a) derived the mean extinction coefficient $\sigma$ of water cloud top by combining the cloud effective radius $R_{e}$ reported by MODIS with the lidar depolarization ratios measured by CALIPSO:

$\sigma=\left(\frac{R_{e}}{R_{e 0}}\right)^{1 / 3}\left\{1+135 \frac{\delta^{2}}{(1-\delta)^{2}}\right\}$

where $R_{e 0}$ equals $1 \mu \mathrm{m}$, and $\delta$ is the layer-integrated depolarization ratio from CALIPSO Level 2 cloud products. Equation (8) is derived from Monte Carlo simulations that incorporate the CALIPSO instrument specifications, viewing geometry, and footprint size. This method (hereafter, we call it "Hu's method") needs collocated water cloud droplet sizes retrieved from MODIS 3.7- $\mu \mathrm{m}$ data for CERES (Minnis et al., 2006). The number of photons scattered into the forward direction increases with particle size. Thus, the chance of a photon at the near-infrared 3.7- $\mu \mathrm{m}$ wavelength being absorbed rather than backscattered to space increases with size. For the same optical depths, water clouds with larger droplets are darker in the near-infrared wavelengths. The effective droplet radius derived from the absorption at 3.7- $\mu \mathrm{m}$ reflects the average size information from the very top part of water clouds (Platnick, 2000), with a vertical penetration depth similar to the CALIPSO lidar signal. So, Hu's method is a 


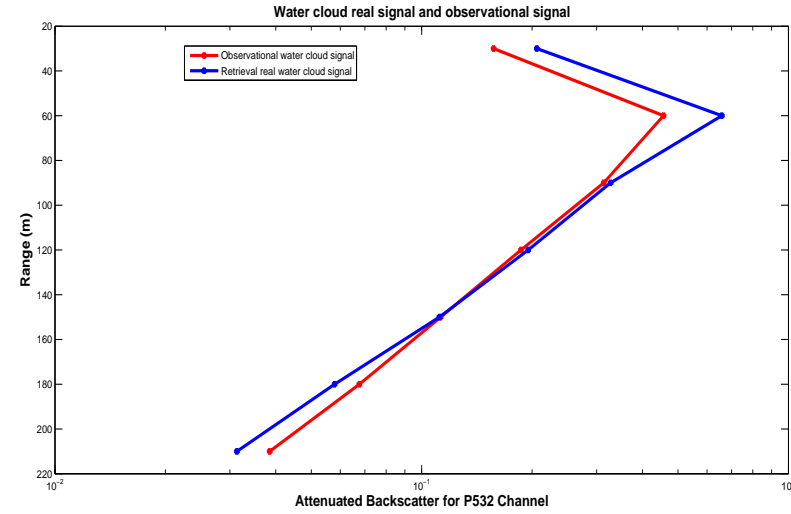

Fig. 3. The retrieved attenuated backscatter signal beneath the water cloud peak return and the observed attenuated backscatter by CALIOP. The red line is the observed (current) water cloud signal and the blue line is the retrieved (corrected or real) cloud signal.

simple and reliable technique that can be used to evaluate and verify the results of the slope method developed in this study during daytime.

In this study, the results of Hu's method are based on four months (January 2008, April 2008, July 2007 and October 2007) MODIS $1 \mathrm{~km}$ cloud data from Aqua and CALIPSO Level 2 cloud dataset. The results of the slope method are based on CALIPSO Level 1 and Level 2 data for the same months. Figure 4 shows a comparison of extinction coefficients derived from the two methods. The $x$-axis is for slope method, and the $y$-axis is for Hu's method. The color values represent the sample numbers. In addition, the black dots are mean values and horizontal thin black lines are the error bars. It is very clear that the differences between the extinction coefficients derived from the two methods are relative larger just when extinctions exceed $40 \mathrm{~km}^{-1}$. We define the absolute relative difference as: $h=\mid \sigma_{\text {slope_method }}-$ $\sigma_{\mathrm{Hu} \text { 's_method }} / \sigma_{\mathrm{Hu} \text { 's_method. }}$ The mean absolute relative difference ranges from $11.4 \%$ to $15 \%$ for the four different months. The difference is largest for January 2008, reaching about 15\%; and smallest for July 2007, reaching about $11.4 \%$. Overall, the average value of the mean absolute relative differences for the four months is about $13.4 \%$.

Figure 5 shows the global distributions of low-level water cloud top extinction coefficient for different months. The left panel depicts Hu's method, and the right panel is for the slope method. It is clear that the global distributions of the extinction coefficients are very similar for two methods. The larger extinction values are located along the coastal regions of the continents, such as the west coasts of South America, North America and Africa. We also found that the frequency of occurrence of water clouds is higher in these coastal regions. Because the MODIS effective radius is more reliable under single-layer cloud conditions, the results of Figs. 4 and 5 are all derived from single-layer cloud samples.
Overall, the global mean extinction coefficients derived from Hu's method are about $31,33,31,32 \mathrm{~km}^{-1}$ for July 2007, October 2007, January 2008 and April 2008, respectively. The corresponding values derived from the slope method are 29, 30, 30 and $31 \mathrm{~km}^{-1}$. Their global mean relative differences are all smaller than $9 \%$, about $1-3 \mathrm{~km}^{-1}$. Thus, we may conclude that the mean extinction values derived from these two methods agree well with each other. However, it is worth noticing that the results in this paper do not include contributions from two kinds of water cloud samples. The first one consists of samples with higher depolarization ratio ( $>0.35)$. As stated at Sect. 2 , a very important parameter in this work is the layer integrated depolarization of water cloud. But, Hu's multiple scattering scheme which we adopted is valid only when the layer-integrated depolarization ratio is smaller than 0.35 . So, in our study, we focus exclusively on water cloud samples with layer-integrated depolarization ratio are smaller than 0.35 . The second kind of water cloud samples that need to be excluded consists of samples with higher extinction coefficients.

A reasonable estimate of the limit of the slope method is that the cloud effective optical depth $(\eta \tau)$ should be less than 3 for the top $100 \mathrm{~m}$. The lidar signal will be completely attenuated within only one vertical range bin of CALIOP when the extinction coefficient of the water cloud is beyond $100 \mathrm{~km}^{-1}$. Water cloud samples with such extreme extinction coefficients were not included in our study. Overall, considering that multiple scattering help reduce the attenuation and enhance the detectability, we can estimate that the upper limit of extinction coefficient retrieval from this approach is about $60 \mathrm{~km}^{-1}$ if we have good SNR (nighttime measurements, lots of averaging). On the safe side, the limit is $30 \mathrm{~km}^{-1}$. This also is the possible reason that caused the relative larger difference between slope method and Hu's method when extinctions exceed $40 \mathrm{~km}^{-1}$. On the other hand, extinction coefficients derived from the Hu's method is less sensitive to the transient response since that method depends only on the depolarization ratio.

\subsection{Comparison of daytime and nighttime extinction coefficients}

In this paper, we assessed the global information of water cloud extinction coefficient during daytime and nighttime by using the slope method developed for this purpose. It is important to notice that day and night differences is different from the diurnal cycle. The CALIPSO data are not able to provide diurnal cycle of clouds. So, the extinction coefficient of water cloud at daytime and nighttime are the all-time mean value for day and night conditions. However, a comparison of daytime and nighttime values is still meaningful. Global statistics of nighttime water cloud optical properties derived in this study constitute a valuable supplement to daytime retrievals from passive remote sensing that depends on 

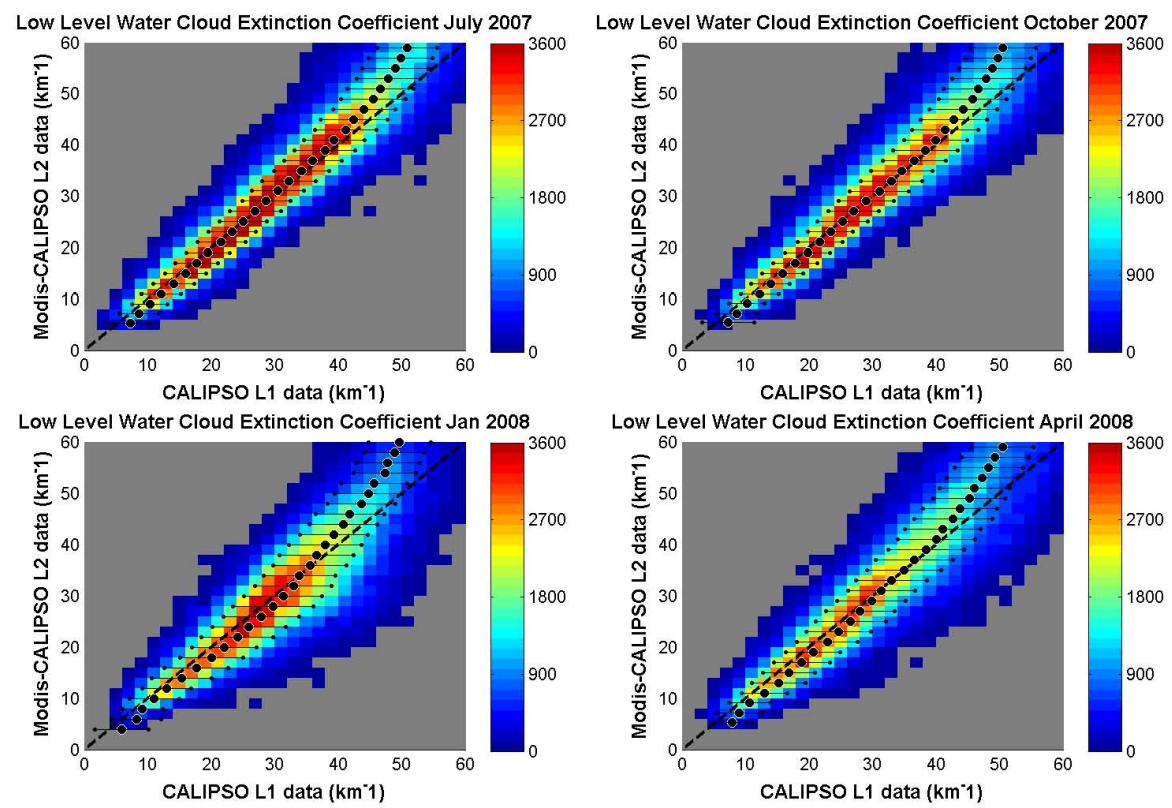

Fig. 4. Comparison of water cloud top mean extinction coefficient by using slope method and Hu's method. The $x$-axis is for slope method, $y$-axis is for Hu's method. Black dots are mean values and horizontal black shorter lines are the error bars.

Table 1. The averaged extinction coefficients and depolarization ratios of low level water cloud from slope method at different subtropical stratocumulus regions.

\begin{tabular}{lcccc|ccccc}
\hline & \multicolumn{4}{c|}{ Extinction $\left(\mathrm{km}^{-1}\right)$} & \multicolumn{4}{c}{ Depolarization } \\
\hline Region & Jul & Oct & Jan & Apr & Jul & Oct & Jan & Apr \\
\hline (1) Californian & D:33 & D:32 & D:30 & D:40 & D:0.224 & D:0.224 & D:0.212 & D:0.246 \\
$10^{\circ} \mathrm{N}-30^{\circ} \mathrm{N} ; 150^{\circ} \mathrm{W}-110^{\circ} \mathrm{W}$ & $\mathrm{N}: 35$ & $\mathrm{~N}: 35$ & $\mathrm{~N}: 30$ & $\mathrm{~N}: 40$ & $\mathrm{~N}: 0.23$ & $\mathrm{~N}: 0.235$ & $\mathrm{~N}: 0.21$ & $\mathrm{~N}: 0.248$ \\
$(2)$ Namibian & D:37 & D:37 & D:34 & D:33 & D:0.239 & D:0.239 & D:0.23 & D:0.226 \\
$30^{\circ} \mathrm{S}-0^{\circ} \mathrm{S} ; 25^{\circ} \mathrm{W}-15^{\circ} \mathrm{E}$ & $\mathrm{N}: 39$ & $\mathrm{~N}: 40$ & $\mathrm{~N}: 37$ & $\mathrm{~N}: 35$ & $\mathrm{~N}: 0.244$ & $\mathrm{~N}: 0.252$ & $\mathrm{~N}: 0.242$ & $\mathrm{~N}: 0.229$ \\
$(3)$ Canarian & D:34 & D:35 & D:26 & D:38 & D:0.236 & D:0.253 & D:0.206 & D:0.243 \\
$10^{\circ} \mathrm{N}-30^{\circ} \mathrm{N} ; 45^{\circ} \mathrm{W}-20^{\circ} \mathrm{W}$ & $\mathrm{N}: 42$ & $\mathrm{~N}: 35$ & $\mathrm{~N}: 27$ & $\mathrm{~N}: 41$ & $\mathrm{~N}: 0.261$ & $\mathrm{~N}: 0.252$ & $\mathrm{~N}: 0.206$ & $\mathrm{~N}: 0.254$ \\
$(4)$ Peruvian & D:31 & D:34 & D:32 & D:31 & D:0.218 & D:0.228 & D:0.22 & D:0.219 \\
$30^{\circ} \mathrm{S}-0^{\circ} \mathrm{S} ; 120^{\circ} \mathrm{W}-70^{\circ} \mathrm{W}$ & $\mathrm{N}: 32$ & $\mathrm{~N}: 37$ & $\mathrm{~N}: 35$ & $\mathrm{~N}: 33$ & $\mathrm{~N}: 0.219$ & $\mathrm{~N}: 0.24$ & N:0.235 & N:0.223 \\
\hline
\end{tabular}

reflected sunlight, and provide additional information about cloud properties.

The global distributions of water cloud extinction coefficients and depolarization ratio at daytime and nighttime in a $2^{\circ}$ by $2^{\circ}$ grid are shown in Figs. 6 and 7. The left panel is for daytime, and the right panel is for nighttime. There are several obvious features in Fig. 6. First, global distributions of the extinction coefficient over the ocean during daytime are very similar to those obtained during nighttime. For example, the larger extinction values (may be reach $40 \mathrm{~km}^{-1}$ ) are located along the coastal regions of the continents, and coincide with the major marine stratocumulus regions. In addition, these regions also exhibit larger cloud droplet number concentrations and smaller mean liquid water paths (Bennartz, 2007). Leon et al. (2008) showed that stratocumulus $(\mathrm{Sc})$ dominated regions exhibit larger day-night difference in cloud properties. And the dynamics and structure of low clouds may exhibit regional differences (Wood et al., 2002). As a result, we picked up four classic subtropical stratocumulus regions (the Californian, Canarian, Namibian, and Peruvian), where strong trade inversions limit mixing between the boundary layer and the free atmosphere, to examine the day-night difference of the extinction coefficients. The geographical definitions of these four regions are the same as those in the study of Leon (Leon et al., 2008). Table 1 lists the extinction coefficients and depolarization ratios of water clouds at day and night for the four regions. The extinction coefficient differences between day and night have 

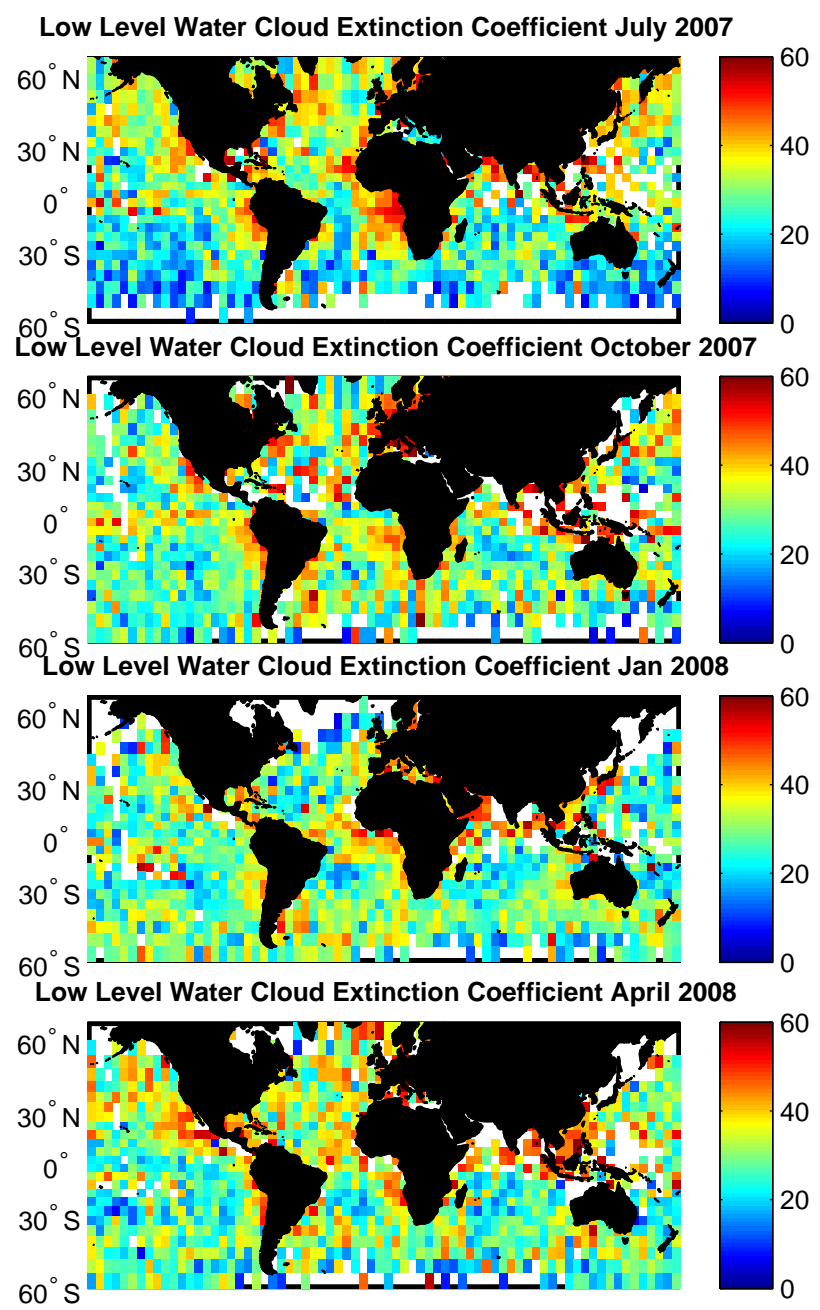

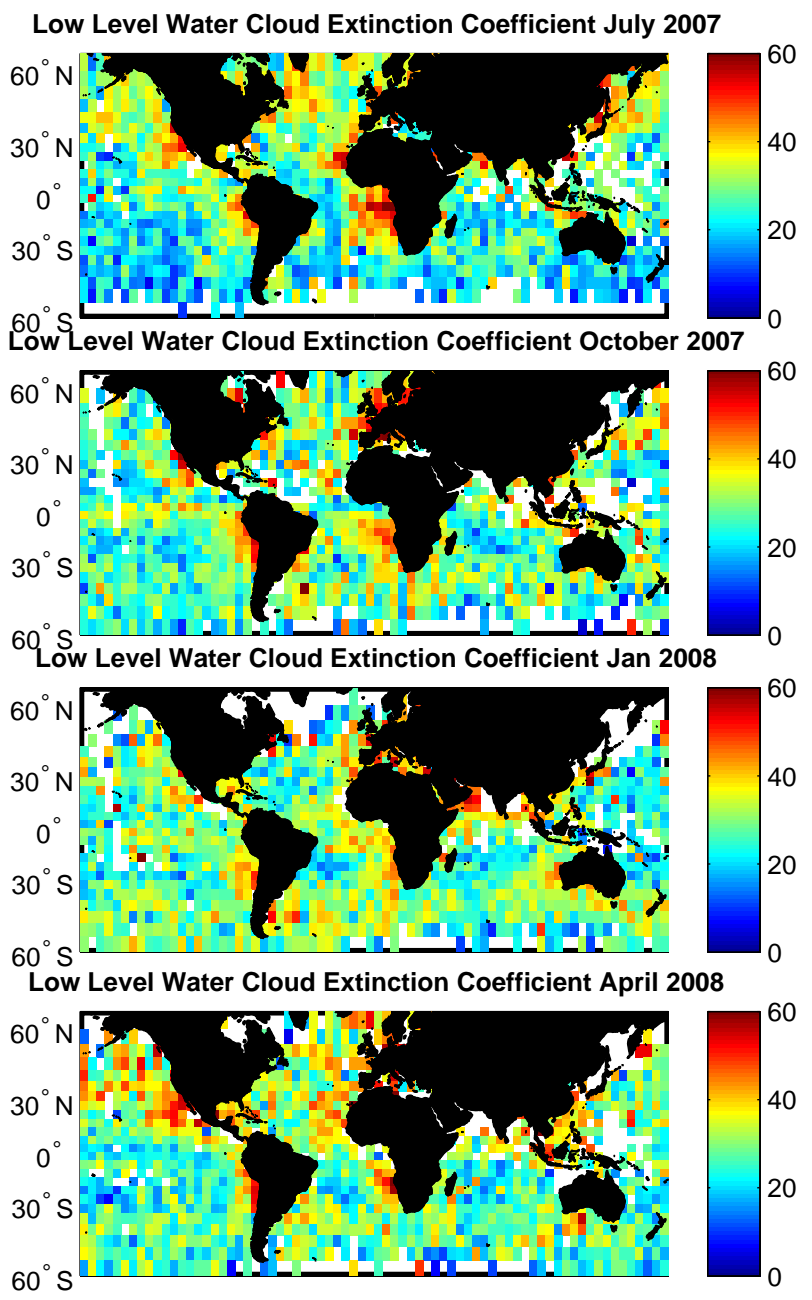

Fig. 5. The global distribution of Low level water cloud mean extinction coefficient at different months derived from the slope method (right) and Hu's method (left).

clear seasonal variability and are mostly negative at these regions. Obvious difference exists for July in the Canarian region, where the difference is about $24 \%\left(-8 \mathrm{~km}^{-1}\right)$. Zero difference exists for January and April in the Californian region, and for October in the Canarian region. In the Californian region, minimum extinctions of day and night both occur in January. Maximum extinctions of day and night both occur in April (about $40 \mathrm{~km}^{-1}$ ), but maximum difference occurs in October (about 9\%). The Namibian region is similar to the Peruvian, the maximum difference between day and night both occur in January, reaching $9 \%$ (about $-3 \mathrm{~km}^{-1}$ ). Maximum extinctions of day and night both are found in October, but the magnitudes are different. The minimum differences between day and night in these two regions both occur in July $(<6 \%)$. In the Canarian region, larger extinction differences occur in July (24\%) and April (8\%). Minimum extinctions of day and night are found in January. However, a contrary tendency is present in the global mean results. That is, the global mean extinction coefficients of water cloud at night are relative lower than those at day. The daytime extinctions are about 29, $3027,29 \mathrm{~km}^{-1}$ for January, April, July and October, respectively. The corresponding nighttime values are $28,28,26$ and $28 \mathrm{~km}^{-1}$. The differences between day and night are all positive and about $1-2 \mathrm{~km}^{-1}$. The maximum difference occurs in July (about 7\%). These results showed clearly that the differences in extinction coefficients between day and night have obvious regionality and vary with season.

Another obvious feature in Figs. 6 and 7 is: global distributions of the water cloud depolarization ratio are similar to that of the extinction coefficient. Larger depolarization ratios correspond to higher extinction values, while smaller depolarization ratios correspond to lower extinction values. Tables 1 and 2 also list the regionally averaged and global 


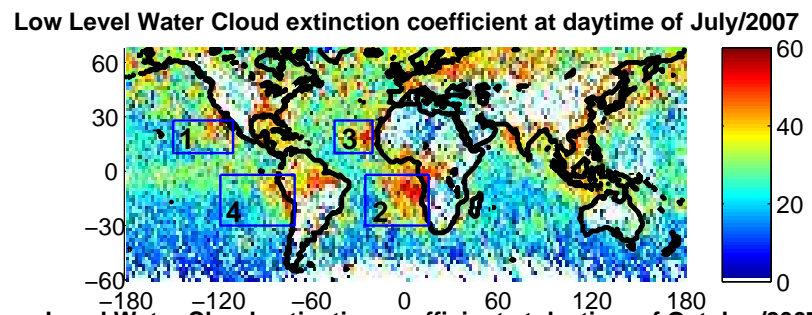

Low Level Water Cloud extinction coefficient at daytime of October/2007

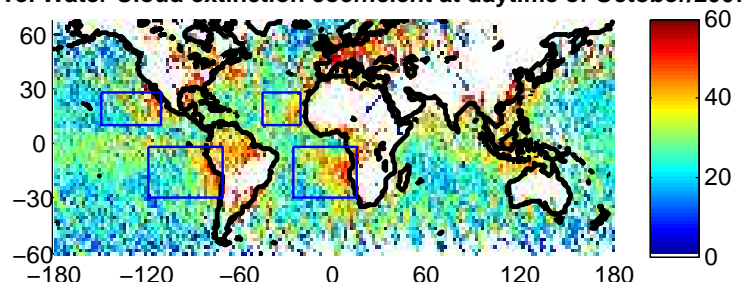

Low Level Water Cloud extinction coefficient at daytime of Jan/2008

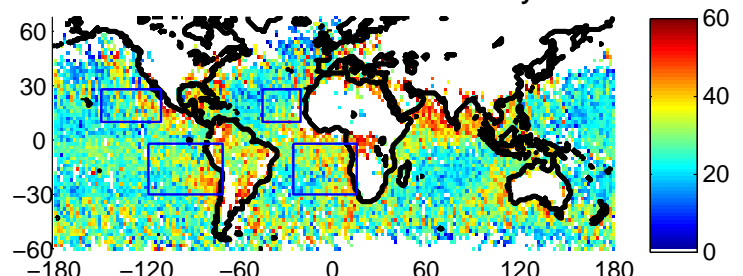

Low Level Water Cloud extinction coefficient at daytime of April/2008

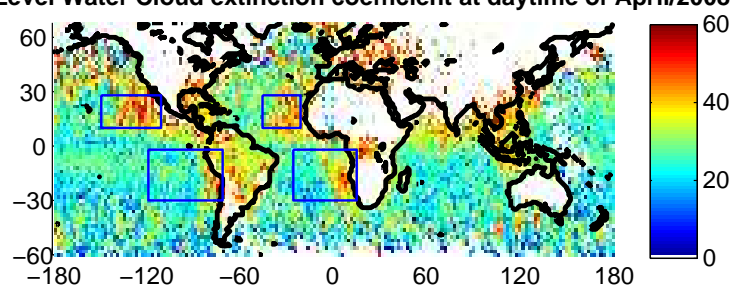

Low Level Water Cloud extinction coefficient at nighttime of July/2007

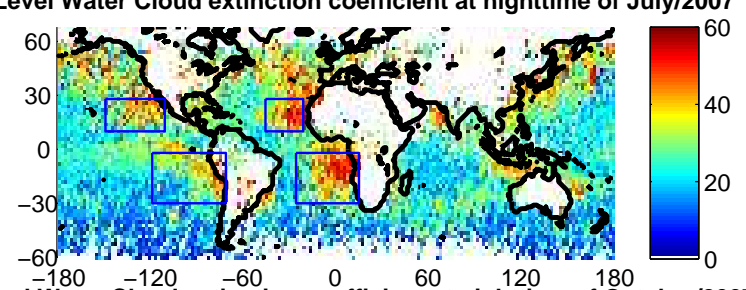

Low Level Water Cloud extinction coefficient at nighttime of October/2007

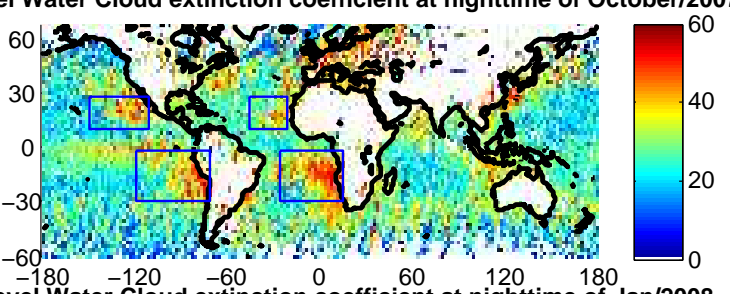

Low Level Water Cloud extinction coefficient at nighttime of Jan/2008

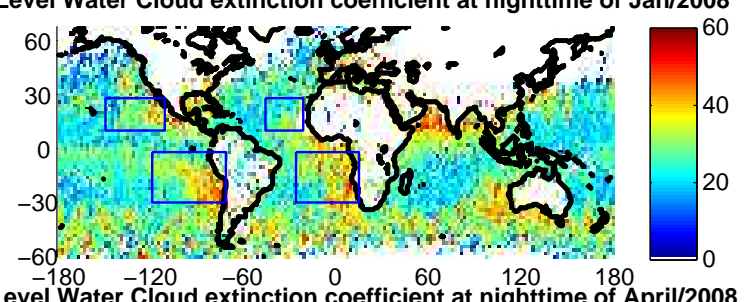

Low Level Water Cloud extinction coefficient at nighttime of April/2008

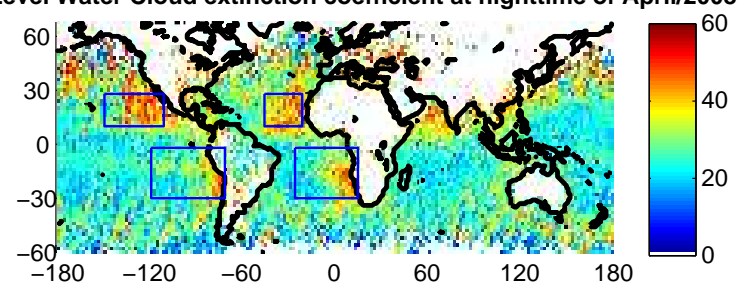

Fig. 6. The global distribution $\left(2^{\circ}\right.$ by $\left.2^{\circ}\right)$ of Low level water cloud mean extinction coefficient at different months derived from the slope method at day (left) and night(right). Sc regions are marked by blue boxes and numbered in Fig. 6. They are: 1, Californian; 2, Namibian; 3, Canarian; 4, Peruvian.

mean depolarization ratios. Overall, the depolarization ratios at four Sc regions are larger than the global mean values, and the differences in depolarization between day and night are negative. However, the differences are positive on the global scale. In addition, the regional depolarization differences are relative smaller $(<0.01)$ than the global mean difference except for several special seasons (such as, October in the Canarian region). To investigate if the differences in depolarization ratio between day and night are small for water clouds at all levels, we also examined the statistics of the global mean depolarization ratio for all level water cloud (with cloud top $<6 \mathrm{~km}$ ). The results, shown in Fig. 8, indicate that the global mean depolarization differences still are small (ranging from 0.009 to 0.019). Sassen et al. (2009) showed that the depolarization in tropospheric ice clouds tends to increase with increasing height/decreasing temperature, as expected from various ground-based lidar studies. We found that the depolarization ratio is height-dependent also in water clouds. As shown in Fig. 8, it appears to de- crease with increasing height/decreasing temperature based on the global mean. The possible reason is: cloud mean liquid water content or liquid water path for clouds with the same thickness decreases with cloud temperature decrease. Therefore, there is weak multiple scattering effect at colder clouds in general. On the other hand, ice cloud depolarizations are controlled mainly by ice crystal shapes.

Table 2 also lists the global mean values of the multiple scattering factor, and the slope of exponential decay of lowlevel water clouds derived from the slope method. The global mean multiple scattering factor of water clouds for different seasons range from 0.41 to 0.45 , and differences between day and night are small, about -0.015 . It is worth noticing that the global mean values of the extinction coefficient during daytime in Tables 1 and 2 are slightly different from the results presented in Sect. 3.1. As stated in Sect. 3.1, because the MODIS effective radius is reliable only under singlelayer cloud conditions, the results of Figs. 4 and 5 are all derived from single-layer cloud samples. However, because 


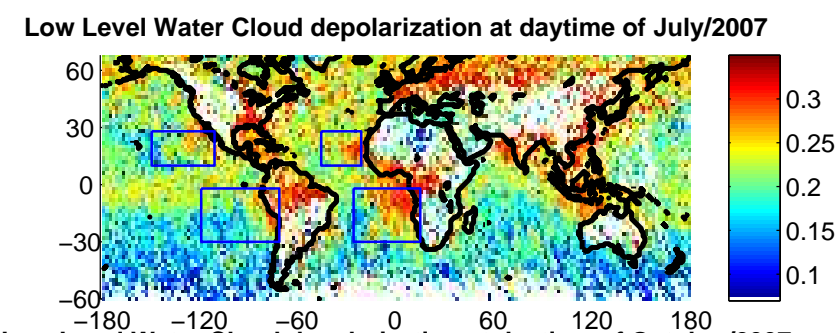

Low Level Water Cloud depolarization at daytime of October/2007

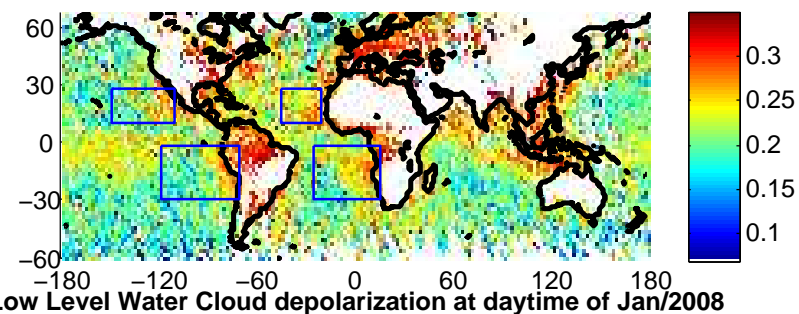

Low Level Water Cloud depolarization at daytime of Jan/2008

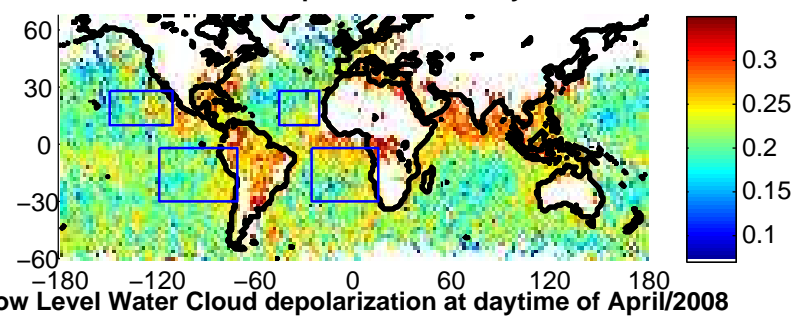

Low Level Water Cloud depolarization at daytime of April/2008

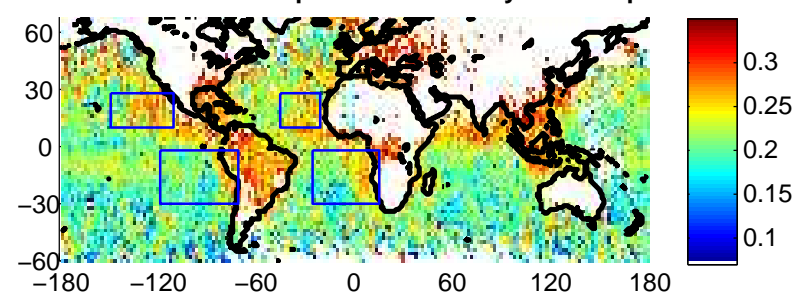

Low Level Water Cloud depolarization at nighttime of July/2007

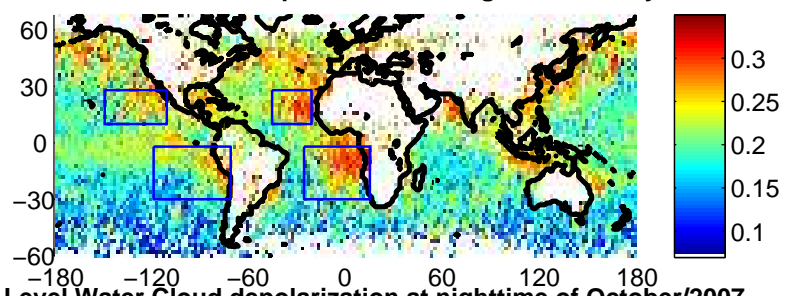

Low Level Water Cloud depolarization at nighttime of October/2007

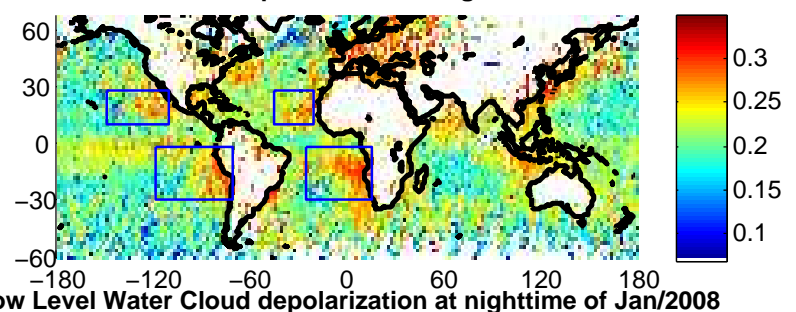

Low Level Water Cloud depolarization at nighttime of Jan/2008

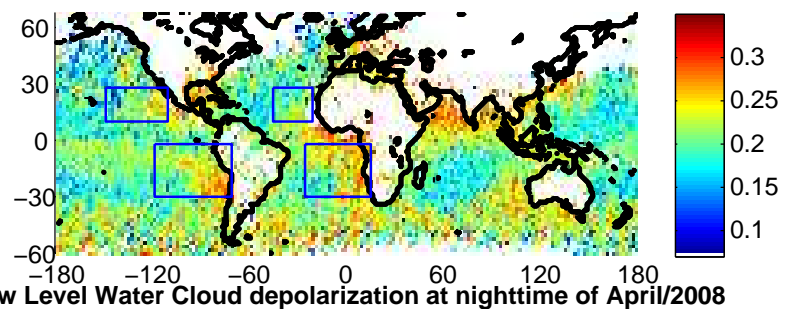

Low Level Water Cloud depolarization at nighttime of April/2008

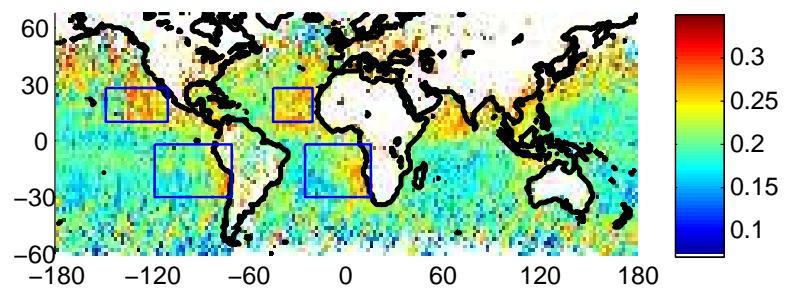

Fig. 7. The global distribution $\left(2^{\circ}\right.$ by $\left.2^{\circ}\right)$ of Low level water cloud depolarization ratio at different months CALIPSO level-2 $333 \mathrm{~m}$ cloud products. The left panel is for daytime; the right panel is for nighttime. Individual Sc regions are outlined in blue boxed and are identified in Fig. 6 and listed in Table 1.

the slope method is not confined to daytime light conditions and single-layer cloud vertical structure, multi-layered cloud samples are also included in this section. Thus, the number of samples considered in Sect. 3.2 is about three times the number of samples in Sect. 3.1. In view of statistics, the results in Tables 1 and 2 are more reasonable and are expected to reflect the mean conditions of low-level water cloud.

\section{Conclusions and discussion}

Boundary layer clouds play an very important role in modulating Earth's climate. In this study, a method based on CALIPSO level 1 attenuated backscatter profile was developed to derive the mean extinction coefficient of low-level water cloud droplets close to cloud top (cloud top $<2 \mathrm{~km}$ ). Although the vertical profile of the extinction coefficient within the entire water cloud layer cannot be derived by this method, it can facilitate retrieval of the droplet number concentration, which has less vertical variation. Generally speaking, the effective droplet radius of water clouds can be directly derived from Eq. (8) when the mean extinction coefficient $\sigma$ was retrieved from CALIPSO level 1 data by the slope method. Then the droplet number concentration also can be derived from an approach similar to that of $\mathrm{Hu}(2007 \mathrm{a})$. However, the errors in the extinction coefficient will be magnified when $\sigma$ is subsequently used to derive the effective radius. Therefore, the slope method need to be improved for retrieving the droplet number concentration in future work. In addition, Bennartz (2007) already assessed the droplet number concentration of marine boundary layer cloud by using satellite datasets and a so-called adiabatic cloud model (Duynkerke et al., 1995; Pawlowska and Brenguier, 2000). In future work, we also can combine the slope method and Bennartz's study to derived cloud droplet 

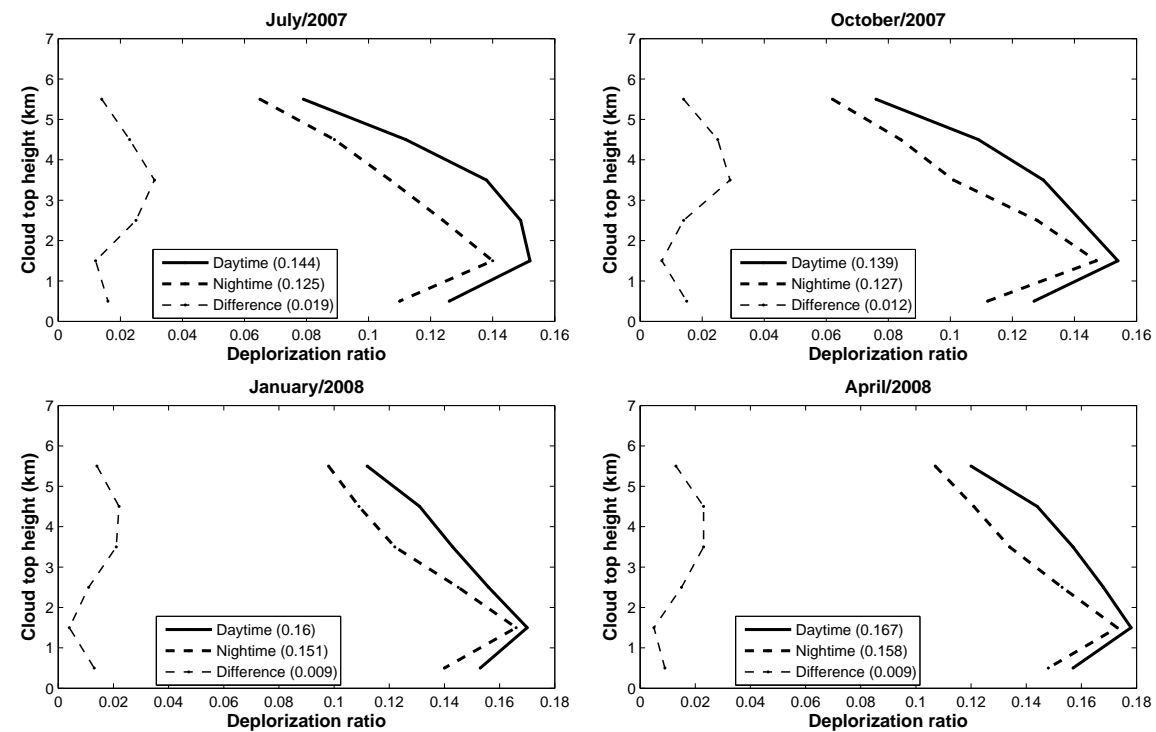

Fig. 8. The height dependency of global mean depolarization ratio for all level water clouds. The solid lines are for daytime, thicker dashed lines are for nighttime, thinner dashed lines are for the difference between day and nighttime. The values in the brackets are the global mean depolarization ratio for all water clouds.

Table 2. The global mean extinction coefficient, eta (multiplescattering factor) and slope (extinction coefficient $\times$ eta) of low level water cloud from slope method.

\begin{tabular}{lcccc}
\hline Para. & Jan/2008 & Apr/2008 & Jul/2007 & Oct/2007 \\
\hline Extinction coefficient $\left(\mathrm{km}^{-1}\right)$ & & & & \\
\hline Day-time & 29 & 30 & 27 & 29 \\
Night-time & 28 & 28 & 26 & 28 \\
difference & 1 & 2 & 1 & 1 \\
\hline Multiple scattering factor & & & & \\
\hline Day-time & 0.411 & 0.41 & 0.426 & 0.41 \\
Night-time & 0.426 & 0.43 & 0.448 & 0.42 \\
difference & -0.015 & -0.02 & -0.022 & -0.01 \\
\hline Slope (km $\left.{ }^{-1}\right)$ & & & & \\
\hline Day-time & 11.3 & 11.3 & 10.6 & 10.8 \\
Night-time & 11.5 & 11.6 & 10.6 & 11.0 \\
difference & -0.2 & -0.3 & 0.0 & -0.2 \\
\hline Depolarization ratio & & & & \\
\hline Day-time & 0.22 & 0.225 & 0.215 & 0.224 \\
Night-time & 0.21 & 0.212 & 0.203 & 0.217 \\
difference & 0.01 & 0.013 & 0.012 & 0.007 \\
\hline
\end{tabular}

number concentration. Such a combination of methods could provide a more effective means of deriving number concentrations under multilayered water cloud conditions or when an absorbing aerosol layer is located above the low level water cloud.
Overall, the new method is useful for retrieving extinction coefficients in clouds with modest and low extinctions (extinction coefficient maybe below $60 \mathrm{~km}^{-1}$ ) when layer-integrated depolarization ratios are smaller than 0.35 . The novel method also was evaluated and compared with the previous method developed by Hu et al. (2007a; "Hu's method"). Comparisons of results show that the extinction values derived from the new method agree well with those derived from Hu's method. The mean absolute relative difference is about $13.4 \%$, and the global mean relative differences are all smaller than $9 \%$, or about $1-3 \mathrm{~km}^{-1}$. We also compared differences in extinction coefficients between day and night at global as well as regional scales. The results showed clearly that the stratocumulus dominated regions exhibit larger day-night differences that are all negative and seasonal. However, a contrary tendency occurs for the global mean results. The global mean extinction coefficients of water clouds at night are relative lower than those at day. The daytime extinctions are about $29,3027,29 \mathrm{~km}^{-1}$ for January, April, July and October, respectively. The corresponding nighttime values are $28,28,26$ and $28 \mathrm{~km}^{-1}$. The differences between day and night are all positive and about $1-2 \mathrm{~km}^{-1}$. The maximum difference occurs in July (about $7 \%$ ). The seasonal variation in global mean multiple scattering factor of water clouds ranges from 0.41 to 0.45 , and differences between day and night are small, about -0.015 . The corresponding global mean depolarization ratio of lowlevel water clouds ranges from 0.2 to 0.23 , and the differences between day and night are also small, about 0.01 . For all-level water clouds (cloud top $<6 \mathrm{~km}$ ), we found that the differences in the global mean depolarization ratio between 
day and night remain small, ranging from 0.009 to 0.019 . Moreover, the global mean depolarization decreases with increasing height/decreasing temperature.

In addition, Sassen et al. (2009) showed that there are significant (about 0.11) average depolarization differences of ice clouds between day and night, which are inconsistent with earlier ground-based data. The significant difference indicates the presence of artifacts in the data set related to the effects of background signals from scattered sunlight in the green laser channel; the gain selection may be one of the reasons. To investigate if the differences in the depolarization ratio between day and night are related to the gain selection, background noise or other factors, we chose different targets (such as water cloud, ice cloud, common aerosol and dust) to analyze their depolarization difference between day and night. Preliminary results indicate that the depolarization differences of spherical particles (water cloud or common aerosols, such as clean continental aerosol) are small $(<0.02)$. Larger differences $(>0.04)$ are found for nonspherical particles (ice clouds or dust). Moreover, the depolarization ratios of targets may be more reliable after April of 2007 (improved data quality). So, we conclude that the larger depolarization differences of ice cloud or dust may be real, and perhaps related to the cloud dynamics. However, these are just preliminary results, and further research is needed to better understand the day-night differences in the CALIPSO depolarization values.

Many studies had shown that aerosols (such as, dust and smoke) have important impact on the variation of cloud properties (such as, effective droplet radius, number concentration and radiation forcing ) (e.g. DeMott et al., 2003; Huang et al., 2006a,b; Su et al., 2008). In this study, the effect of aerosols on cloud properties was not considered. That is, the slope of the exponential decay of the validated water cloud attenuated backscatter profile may be somewhat influenced by the aerosol loading, particularly over the Western coast of Africa (smoke is abundant due to frequent burning activities). Hence, more studies about the interaction between aerosol and clouds over these regions (higher aerosol optical depth) would be needed in the future.

Acknowledgements. This work is supported by the NASA radiation science program and the CALIPSO project. In addition, this work is also supported by the National Science Foundation of China under Grant No. 40725015 and 40633017. Here, the authors want to also thank Hal Maring and David Considine of NASA Headquarters for discussions and support.

Edited by: Q. Fu

\section{References}

Albrecht, B. A., Randall, D. A., and Nicholls, S.: Observations of marine stratocumulus clouds during FIRE, B. Am. Meteor. Soc., 69, 618-626, 1988.

Bennartz, R.: Global assessment of marine boundary layer cloud droplet number concentration from satellite, J. Geophys. Res., 112, D02201, doi:10.1029/2006JD007547, 2007.

Betts, A. K. and Boers, R.: A cloudiness transition in a marine boundary layer, J. Atmos. Sci., 47, 1480-1497, 1990.

Boers, R. and Mitchell, R. M.: Absorption feedback in stratocumulus clouds: Influence on cloud top albedo, Tellus, 46A, 229-241, 1994.

Brenguier, J., Pawlowska, H., Schuller, L., Preusker, R., Fischer, J., and Fouquart, Y.: Radiative properties of boundary layer clouds: Droplet effective radius versus number concentration, J. Atmos. Sci., 57, 803-821, 2000.

Cao, X., Roy, G., Roy, N., and Bernier, R.: Comparison of the relationships between lidar integrated backscattered light and accumulated depolarization ratios forlinear and circular polarization for water droplets, fog-oil and dust, Appl. Opt., 48, 4130-4141, 2009.

Chand, D., Anderson, T. L., Wood, R., Charlson, R. J., Hu, Y., and Liu, Z.: Quantifying above-cloud aerosol using spaceborne lidar for improved understanding of cloudy-sky direct climate forcing, J. Geophys. Res., 113, D13206, doi:10.1029/2007JD009433, 2008.

Charlson, R. J., Lovelock, J. E., Andreae, M. O., and Warren, S. G.: Oceanic phytoplankton, atmospheric sulphur, cloud albedo and climate, Nature, 326, 655-661, 1987.

DeMott, P. J., Sassen, K., Poellot, M. R., Baumgardner, D., Rogers, D. C., Brooks, S. D., Prenni, A. J., and Kreidenweis, S. M.: African dust aerosols as atmospheric ice nuclei, Geophys. Res. Lett., 30(14), 1732, doi:10.1029/2003GL017410, 2003.

Derr, V. E.: Estimation of the extinction coefficient of clouds from multiwavelength lidar backscatter measurements, Appl. Opt., 19, 2310-2314, 1980.

Duynkerke, P., Zhang, H., and Jonker, P.: Microphysical and turbulent structure of nocturnal stratocumulus as observed during ASTEX, J. Atmos. Sci., 52, 2763-2777, 1995.

Fouquart, Y., Buriez, J. C., and Herman, M.: The influence of clouds on radiation: A climate modeling perspective, Rev. Geophys., 28, 145-166, 1990.

Fox, N. I. and Illingworth, A. J.: The retrieval of stratocumulus cloud properties by ground-based cloud radar, J. Appl. Meteorol., 36, 485-492, 1997.

Hansen, J. E.: Multiple scattering of polarized light in planetary atmospheres: Part I. The doubling Method, J. Atmos. Sci., 28, 120-125, 1971a.

Hansen, J. E.: Multiple scattering of polarized light in planetary atmospheres: Part II. Sunlight reflected by terrestrial water clouds, J. Atmos. Sci., 28, 1400-1426, 1971 b.

Hartmann, D. L. and Short, D. A.: On the use of Earth radiation budget statistics for studies of clouds and climate, J. Atmos. Sci., 37, 1233-1250, 1980.

Hartmann, D. L., Ockert-Bell, M. E., and Michelsen, M. L.: The effect of cloud type on Earth's enery balance: Global analysis, J. Clim., 5, 1281-1304, 1992.

Hu, Y., Winker,D. W., Yang, P., Baum, B., Poole, L., and Vann, L.: Identification of cloud phase from PICASSO-CENA lidar 
depolarization: A multiple scattering sensitivity study, J. Quant. Spectrosc. Radiat. Trans., 70, 569-579, 2001.

Hu, Y., Liu, Z., Winker, D., Vaughan, M., Noel, V., Bissonnette, L., Roy, G., and McGill, M.: A simple relation between lidar multiple scattering and depolarization for water clouds, Opt. Lett., 31, 1809-1811, 2006.

Hu, Y., Vaughan, M., McClain, C., Behrenfeld, M., Maring, H., Anderson, D., Sun-Mack, S., Flittner, D., Huang, J., Wielicki, B., Minnis, P., Weimer, C., Trepte, C., and Kuehn, R.: Global statistics of liquid water content and effective number concentration of water clouds over ocean derived from combined CALIPSO and MODIS measurements, Atmos. Chem. Phys., 7, 3353-3359, doi:10.5194/acp-7-3353-2007, 2007a.

Hu, Y., Vaughan, M., Liu, Z., Powell, K., and Rodier, S.: Retrieving Optical Depths and Lidar Ratios for Transparent Layers Above Opaque Water Clouds From CALIPSO Lidar Measurements, IEEE Trans. Geosci. Remote Sens. Lett., 4, 523-526, 2007b.

Hu, Y., Vaughan, M., Liu, Z., Lin, B., Yang, P., Flittner, D., Hunt, W., Kuehn, R., Huang, J., Wu, D., Rodier, S., Powell, K., Trepte, C., and Winker, D.: The depolarization-attenuated backscatter relation: CALIPSO lidar measurements vs. theory, Opt. Express, 15, 5327-5332, 2007c.

Hu, Y., Powell, K., Vaughan, M., Tepte, C., Weimer, C., Beherenfeld, M., Young, S., Winker, D., Hostetler, C., Hunt, W., Kuehn, R., Flittner, D., Cisewski, M., Gibson, G., Lin, B., and MacDonnell, D.: Elevation-In-Tail (EIT) technique for laser altimetry, Opt. Express, 15, 14504-14515, 2007d.

Huang, J., Minnis, P., Lin, B., Wang, T., Yi, Y., Hu, Y., SunMack, S., and Ayers, K.: Possible influences of Asian dust aerosols on cloud properties and radiative forcing observed from MODIS and CERES, Geophys. Res. Lett., 33, L06824, doi:10.1029/2005GL024724, 2006a.

Huang, J., Lin, B., Minnis, P., Wang, T., Wang, X., Hu, Y., Yi, Y., and Ayers, J. R.: Satellite-based assessment of possible dust aerosols semi-direct effect on cloud water path over East Asia, Geophys. Res. Lett., 33, L19802, doi:10.1029/2006GL026561, 2006b.

Hunt, W. H., Winker, D. M., Vaughan, M. A., Powell, K. A., Lucker, P. L., and Weimer, C.: CALIPSO lidar description and performance assessment, J. Atmos. Oceanic Technol., 26, 1214-1228, 2009.

Illingworth, A. J., Hogan, R. J., O'Connor, E. J., Bouniol,D., Delano, J.,Pelon, J., Protat, A.,Brooks, M. E., Gaussiat, N., Wilson, D. R.,Donovan, D. P.,Klein Baltink, H.,van Zadelhoff, G. J.,Eastment, J. D., Goddard, J. W. F.,Wrench, C. L.,Haeffelin, M., Krasnov, O. A., Russchenberg, H. W. J., Piriou, J. M., Vinit, F., Seifert, A.,Tompkins, A. M., and Willn, U.: Cloud-Net: Continuous evaluation of cloud profiles in seven operational models using ground-based observations, Bull. Amer. Meteorol. Soc., 88, 883-898, 2007.

Kiehl, J. T.: Sensitivity of a GCM climate simulation to differences in continental versus maritime cloud drop size, J. Geophys. Res., 99(23), 107-123, 1994.

Kim, S. W., Berthier, S., Raut, J. C., Chazette, P., Dulac, F., and Yoon, S. C.: Validation of aerosol and cloud layer structures from the space-borne lidar CALIOP using a ground-based lidar in Seoul, Korea, Atmos. Chem. Phys., 8, 3705-3720, doi:10.5194/acp-8-3705-2008, 2008.
Leon, D. C., Wang, Z., and Liu, D.: Climatology of drizzle in marine boundary layer clouds based on 1 year of data from Cloudsat and Cloud-Aerosol Lidar and Infrared Pathfinder Satellite Observations (CALIPSO), J. Geophys. Res., 113, D00A14, doi:10,1029/2008JD009835, 2008.

Mamouri, R. E., Amiridis, V., Papayannis, A., Giannakaki, E., Tsaknakis, G., and Balis, D. S.: Validation of CALIPSO spaceborne-derived attenuated backscatter coefficient profiles using a ground-based lidar in Athens, Greece, Atmos. Meas. Tech., 2, 513-522, doi:10.5194/amt-2-513-2009, 2009.

Masunaga, H., Nakajima, T. Y., Nakajima, T., Kachi, M., Oki, R., and Kuroda, S.: Physical properties of maritime low clouds as retrieved by combined use of Tropical Rainfall Measurement Mission Microwave Imager and Visible/Infrared Scanner: 1. Algorithm, J. Geophys. Res., 107(D10), 4083, doi:10.1029/2001JD000743, 2002a.

Masunaga, H., Nakajima, T. Y., Nakajima, T., Kachi, M., and Suzuki, K.: Physical properties of maritime low clouds as retrieved by combined use of TRMM Microwave Imager and Visible/Infrared Scanner: 2. Climatology of warm clouds and rain, J. Geophys. Res., 107(D19), 4367, doi:10.1029/2001JD001269, 2002b.

McGill, M. J., Vaughan, M., Trepte, C. R., Hart, W. D., Hlavka, D. L., Winker, D. M., Kuehn, R.: Airborne validation of spatial properties measured by the CALIPSO lidar, J. Geophys. Res., 112, D20201, doi:10.1029/2007JD008768, 2007.

Minnis, P., Geier, E., Wielicki, B., Mack, S. S., Chen, Y., Trepte, Q. Z., Dong, X. Q., Doelling, D. R., Ayers, J. K., and Khaiyer, M. M.: Overview of CERES cloud properties from VIRS and MODIS data, Proc. AMS 12th Conf. Atmos. Radiation, Madison, WI, July 10-14, CD-ROM, J2.3., 2006.

Mona, L., Amodeo, A., D’Amico, G., and Pappalardo, G.: First comparisons between CNR-IMAA multi-wavelength Raman lidar measurements and CALIPSO measurements, Proc. SPIE, 6750, 675010, doi:10.1117/12.738011, 2007.

O'Connor, E. J., Hogan, R. J., and Illingworth, A. J.: Retrieving stratocumulus drizzle parameters using Doppler radar and lidar, J. Appl. Meteorol., 44, 14-27, 2005.

Platnick, S.: Vertical photon transport in cloud remote sensing problems, J. Geophys. Res., 105(22), 919-935, 2000.

Platt, C. M. R.: Remote sounding of high clouds: I. Calculation of visible and infrared optical properties from lidar and radiometer measurements, J. Appl. Meteor., 18, 1130-1143, 1979.

Platt, C. M. R.: Remote sounding of high clouds: III. Monte Carlo calculations of multiple-scattered lidar returns, J. Atmos. Sci., 38, 156-167, 1981.

Randall, D. A., Coakley Jr., J. A., Fairall, C. W., Kropfli, R. A., and Lenschow, D. H.: Outlook for research on subtropical marine stratiform clouds, B. Am. Meteor. Soc., 65, 1290-1301, 1984.

Sassen, K. and Zhu, J.: A global survey of CALIPSO linear depolarization ratios in ice clouds: Initial findings, J. Geophys. Res., 114, D00H07, doi:10.1029/2009JD012279, 2009.

Schüller, L., Brenguier, J., and Pawlowska, H.: Retrieval of microphysical, geometrical, and radiative properties of marine stratocumulus from remote sensing, J. Geophys. Res., 108(D15), 8631, doi:10.1029/2002JD002680, 2003.

Schüller, L., Bennartz, R., Fischer, J., and Brenguier, J.: An algorithm for the retrieval of droplet number concentration and geometrical thickness of stratiform marine boundary layer clouds 
applied to MODIS radiometric observations, J. Appl. Meteorol., 44, 28-38, 2005.

Slingo, A.: Sensitivity of the Earths radiation budget to changes in low clouds, Nature, 343, 49-51, 1990.

Su, J., Huang, J., Fu, Q., Minnis, P., Ge, J., and Bi, J.: Estimation of Asian dust aerosol effect on cloud radiation forcing using FuLiou radiative model and CERES measurements, Atmos. Chem. Phys., 8, 2763-2771, doi:10.5194/acp-8-2763-2008, 2008.

Tao, Z., Mccormick, M. P., and Wu, D.: A comparison method for spaceborne and ground-based lidar and its application to the CALIPSO lidar, Apply Phys. B, 91, 639-644, 2008.

Wang, Z. and Sassen, K.: Cloud type and property retrieval using multiple remote sensors, J. Appl. Meteor., 40, 1665-1682, 2001.

Wang, Z., Sassen, K., Whiteman, D., and Demoz, B.: Studying altocumulus plus virga with ground-based active and passive remote sensors, J. Appl. Meteor., 43, 449-460, 2004.

Westbrook, C. D., Hogan, R. J., O'Connor, E. J., and Illingworth, A. J.: Estimating drizzle drop size and precipitation rate using two-colour lidar measurements, Atmos. Meas. Tech., 3, 671681, doi:10.5194/amt-3-671-2010, 2010.
Winker, D. M., Pelon, J. R., and McCormick, M. P.: The CALIPSO mission: Spaceborne lidar for observation of aerosols and clouds, Proc. SPIE, 4893, 1-11, doi:10.1117/12.466539, 2003.

Wood, R.: Drizzle in stratiform boundary layer clouds. Part I: Vertical and horizontal structure, J. Atmos. Sci., 62, 3011-3033, 2005a.

Wood, R.: Drizzle in stratiform boundary layer clouds. Part II: Microphysical aspects, J. Atmos. Sci., 62, 3034-3050, 2005 b.

Wood, R. and Hartmann, D. L.: Spatial variability of liquid water path in marine low cloud: The importance of mesoscale cellular convection, J. Clim., 19, 1748-1764, 2006.

Wood, R., Bretherton, C. S., and Hartmann, D. L.: Diurnal cycle of liquid water path over the subtropical and tropical oceans, Geophys. Res. Lett., 29, doi:10.1029/2002GL015371, 2002. 